\title{
Mechanisms of lower oesophageal sphincter incompetence in patients with symptomatic gastrooesophageal reflux
}

\author{
J DENT, R H HOLLOWAY, J TOOULI, AND W J DODDS \\ From the Departments of Medicine and Surgery, Flinders Medical Centre, Bedford Park, South Australia
}

SUMmaRy Patterns of lower oesophageal sphincter (LOS) function associated with the onset of 644 reflux episodes were recorded and analysed in 67 patients referred for evalution of gastrooesophageal reflux (GOR). Patients were studied recumbent, for one hour before and four hours after a standard meal. Transient LOS relaxation was the most prevalent mechanism and overall accounted for $82 \%$ of reflux episodes. With increasing severity of oesophagitis, absent basal LOS pressure became a progressively more common mechanism, accounting for $23 \%$ of episodes in the patients with severe oesophagitis. Patients commonly exhibited more than one mechanism. The timing of most $(69 \%)$ LOS relaxations associated with reflux was not compatible with triggering by swallowing. Prolonged transient LOS relaxations were associated with inhibition of oesophageal peristalsis suggesting that this response is produced by neural inhibition. This study suggests the primary importance of transient LOS relaxations as the cause of GOR across the spectrum of severity of reflux disease.

For many years gastrooesophageal reflux (GOR) was generally believed to result from lower oesophageal sphincter (LOS) incompetence caused by defective basal LOS tone..$^{1-4}$ This concept, however, fails to account for the substantial proportion of patients with reflux disease in whom resting LOS pressure is normal. ${ }^{5-7}$ A recent study has shown that GOR in normal subjects occurs almost exclusively as a result of transient LOS relaxation, rather than from defective basal LOS pressure. ${ }^{8}$ In a subsequent study of 10 selected patients with erosive peptic oesophagitis, transient LOS relaxation accounted for $65 \%$ of reflux episodes, the remainder of reflux episodes occurring during prolonged periods of absent or low basal LOS pressure. ${ }^{9}$ The aims of the present study were to: (a) investigate possible variation in the mechanisms of GOR within a large group of patients exhibiting a spectrum of severity of reflux disease: and (b) analyse in detail, patterns of oeso-

Address for correspondence: Dr John Dent, Director, Gastroenterology Unit, Royal Adelaide Hospital, North Terrace, Adelaide, South Australia, 5000. Received for publication 29 February 1988. phageal motility associated with reflux events in an effort to gain insight into the mechanism of transient LOSRs.

\section{Methods}

\section{STUDY GROUP}

The study protocol outlined below was approved by the Ethical Review Committee of Flinders Medical Centre in March 1977. The patients included in the study were referred because they represented a problem in clinical management. The reasons for referral included troublesome or atypical symptoms, atypical oesophageal ulceration, and preoperative assessment for antireflux surgery. Patients with a previous vagotomy, gastric resection, gastroenterostomy, or antireflux surgery were excluded. This report describes the findings in 67 patients in whom technically satisfactory oesophageal manometric and $\mathrm{pH}$ recordings were obtained. Studies in 23 other patients were unsatisfactory because of technical failure of $\mathrm{pH}$ electrodes, difficulties with intubation, or failure of the subject to complete the 
full monitoring period because of intolerance to the catheter assembly.

EVALUATION OF PATIENTS

Patients were assessed initially by history and physical examination. An upper gastrointestinal endoscopy was carried out if not done previously and the results clearly documented within six months of referral. Oesophageal motility and $\mathrm{pH}$ studies were done at least one week after endoscopy. When a clear association between symptoms and spontaneous oesophageal acidification was not established during the motility and $\mathrm{pH}$ study, a Bernstein test was done immediately after the completion of the manometric study.

Based on the clinical history, endoscopic findings, and the relationship of symptoms to oesophageal acidification, the patients were classified into four groups: those judged not to have symptomatic GOR (group A), and those diagnosed as having symptomatic GOR of three levels of severity (groups B, C, D). Group A patients had atypical symptoms, a normal mucosal appearance at endoscopy, with symptoms that could not be reproduced during oesophageal acidification. Group B patients had no endoscopic evidence of oesophageal erosions or ulceration but their symptoms were clearly provoked by oesophageal acidification during either spontaneous acid reflux (six patients) or subsequent acid infusion (Bernstein) testing (14 patients). Group C patients exhibited patchy erosions or non-confluent ulceration. Group D patients had evidence of confluent ulceration, columnar epithelium (five patients), or a chronic oesophageal ulcer.

\section{MANOMETRIC AND OESOPHAGEAL PH}

RECORDINGS

Oesophageal motility was monitored using an 8lumen manometric assembly that incorporated a sleeve sensor. ${ }^{10}$ The $6 \mathrm{~cm}$ long sleeve sensor was positioned so that it straddled the LOS. Two side holes 1 and $3 \mathrm{~cm}$ below the distal margin of the sleeve recorded intragastric pressure. Side holes at the upper margin of the sleeve and 7,14 , and $21 \mathrm{~cm}$ more proximally monitored motor activity of the oesophageal body. The most proximal side hole, located in the pharynx, monitored swallows. Each lumen was connected in series with a Bell and Howell (no 4-3271) pressure transducer and perfused with distilled water by a low compliance pneumo-hydraulic pump. The LOS and gastric manometric channels were perfused at $0.5 \mathrm{ml} / \mathrm{min}$. The oesophageal body and pharyngeal channels were perfused at 0.13 $\mathrm{ml} / \mathrm{min}$, a rate selected to yield reliable recognition of the occurrence of oesophageal body and pharyngeal contractions yet minimise alterations to the patterns of oesophageal acid clearance or the rate of primary or secondary peristalsis.

Oesophageal $\mathrm{pH}$ was monitored using either a Beckman (no 39042) or a Microelectrodes (no M1-506) unipolar intraluminal $\mathrm{pH}$ electrode positioned $5 \mathrm{~cm}$ above the proximal margin of the LOS. The electrode was calibrated in buffers of $\mathrm{pH} 4$ and 7 before and after each study. If electrode drift in excess of $0.6 \mathrm{pH}$ units occurred, the study was rejected. Correction for electrode drifts of less than $0.6 \mathrm{pH}$ units was made on the assumption that the drift was linear during the study. Signals from the pressure transducers and $\mathrm{pH}$ meter (Electronics Instuments Ltd, no 2320) were processed and recorded on a Devices M19 chart recorder at a paper speed of $80 \mathrm{~mm} / \mathrm{minute}$.

\section{STUDY PROTOCOL}

Patients were studied after a four hour fast. This fasting period was selected with the aim of achieving a late fed state of motor activity for the first hour of the study and thereby avoid the cyclical changes of LOS pressure associated with the phases of the migrating motor complex, that occur during fasting." Anticholinergic or antisecretory drugs were stopped 36 hours before the study, antacids were not allowed for 12 hours before the start of recordings, and smoking was not permitted on the day of the study. The patients remained recumbent, either supine or on their side, except while eating the meal and when voiding. After one hour of baseline recordings, the patients then ate a standard meal consisting of soft meat or fish, mashed potatoes, cooked vegetables, ice cream and $180 \mathrm{ml}$ of milk. After completion of the meal, oesophageal motility and $\mathrm{pH}$ recordings were continued for an additional 4 hours. Patients were not permitted to doze during the recording because of the effect of sleep on patterns of reflux. ${ }^{812}$ Patients indicated to the observer when they had symptoms such as heartburn, regurgitation or chest pain, and this was noted on the chart.

\section{DATA ANALYSIS}

The oesophageal $\mathrm{pH}$ tracing was analysed manually to determine the time that $\mathrm{pH}$ was less than 4 . Reflux episodes were also identified and counted, being defined as either a drop of oesophageal $\mathrm{pH}$ below 4 for at least four seconds, or if oesophageal $\mathrm{pH}$ was already below 4 , as a decrease of at least $1 \mathrm{pH}$ unit sustained for at least four seconds. The duration of acidification after reflux episodes was measured as the time taken for oesophageal $\mathrm{pH}$ to return to 4 . Excluded from rigid application of these criteria was the brief upward spike of $\mathrm{pH}$ associated with peristalsis. This spike could be differentiated from a reflux event by its shape, the pattern of return of 
oesophageal $\mathrm{pH}$ to near preswallow levels, and its association with peristalsis. Infrequently, oseophageal $\mathrm{pH}$ drifted downwards during a period of several minutes and dropped below $\mathrm{pH} 5$ and occasionally $\mathrm{pH} 4$. These $\mathrm{pH}$ drifts were included in analysis of the duration of oesophageal acid exposure but were not scored as reflux episodes.

The onset of the usually abrupt reduction of oesophageal $\mathrm{pH}$ associated with GOR was used as the reference for analysis of the motility events associated with reflux. For all reflux episodes the following variables of motility were measured: (1) LOS pressure at the onset of acid reflux; (2) the pattern of LOS pressure for 30 seconds before reflux; and (3) the pattern of pharyngeal and oesophageal motility for 30 seconds before the onset of reflux.

Basal end expiratory LOS pressure, referenced to intragastric pressure, was determined at 15 minute intervals by taking a one minute visual mean of the tracing. Overall mean values of LOS pressure were derived for each patient for the one hour before and four hours after the meal.

Statistical analysis of the rate of reflux episodes and the duration of oesophageal acid exposure used the Wilcoxon's signed-rank test and the Mann-Whitney U-test. Differences in the proportions of the reflux episodes associated with the major mechanism of LOS incompetence were assessed by $\chi^{2}$ analysis. Values for basal LOS pressure were assessed by analysis of variance and the Student's $t$ test for unpaired values.

\section{Results}

\section{ACID REFLUX PATTERN}

Overall, the results of oesophageal $\mathrm{pH}$ monitoring supported the grouping of patients based on the clinical and endoscopic assessment of the severity of GOR disease. Patients in Groups B, C, and D judged to have symptomatic GOR, had significantly more postprandial oesophageal acid exposure than did patients in Group A judged not to have symptomatic reflux disease $(\mathrm{p}<0.01)$ (Table). The patients with reflux disease exhibited a progressive increase in postprandial reflux rate and oesophageal acid exposure with increasing severity of oesophagitis but differences among these latter three groups were not statistically significant. The reflux rate and duration of acid exposure increased significantly after the meal in all groups.

RELATIONSHIP OF LOS PRESSURE TO REFLUX Lower oesophageal sphincter pressure during the period surrounding each reflux episode could be analysed in 644 of 691 episodes (93\%). The remaining $7 \%$ could not be analysed because of movement arte-
Table 1 Rate of reflux episodes and duration of oesophageal acid exposure

\begin{tabular}{|c|c|c|c|c|}
\hline \multirow{2}{*}{$\begin{array}{l}\text { Patient } \\
\text { group } \\
\text { (no) }\end{array}$} & \multicolumn{2}{|c|}{ Rate of reflux episodes } & \multicolumn{2}{|c|}{ Duration of acid exposure } \\
\hline & $\begin{array}{l}\text { Preprandial } \\
(n / h)\end{array}$ & $\begin{array}{l}\text { Postprandial } \\
(n / h)\end{array}$ & $\begin{array}{l}\text { Preprandial } \\
(\%)\end{array}$ & $\begin{array}{l}\text { Postprandial } \\
(\%)\end{array}$ \\
\hline $\begin{array}{l}\text { Group A } \\
\quad(n=15)\end{array}$ & $0 \cdot 2(0 \cdot 1)$ & $0 \cdot 5(0 \cdot 1)^{*}$ & $0.6(0.4)$ & $0.9(0.4)^{*}$ \\
\hline $\begin{array}{l}\text { Group B } \\
\quad(n=20)\end{array}$ & $1 \cdot 1(0 \cdot 8)$ & $2 \cdot 2(0 \cdot 2) \dagger \ddagger$ & $1 \cdot 3(1 \cdot 0)$ & $9 \cdot 0(3 \cdot 8) \dagger \ddagger$ \\
\hline $\begin{array}{l}\text { Group C } \\
\quad(n=18)\end{array}$ & $1 \cdot 1(0 \cdot 4)$ & $2 \cdot 9(0 \cdot 5) \dagger \ddagger$ & $2 \cdot 3(1 \cdot 2)$ & $10 \cdot 7(2 \cdot 8) \dagger \ddagger$ \\
\hline Group D & $1 \cdot 1(0 \cdot 4) \ddagger$ & $4.9(1 \cdot 0) \dagger \ddagger$ & $1 \cdot 7(0 \cdot 9) \ddagger$ & $18 \cdot 6(5 \cdot 1) \dagger \ddagger$ \\
\hline
\end{tabular}

Data expressed as $\times(\mathrm{SE})$. Differed significantly from preprandial value: ${ }^{*} p<0.05, \dagger p<0.01$. Differed significantly from Group $A$ value: $\ddagger \mathrm{p}<0 \cdot 01$.

fact or several motor events occurring within a few seconds surrounding the onset of the reflux event.

A consistent relationship existed between LOS pressure and the occurrence of reflux. In $95 \%$ of reflux episodes LOS pressure was undetectable $(<2$ $\mathrm{mmHg}$ ) at the onset of the $\mathrm{pH}$ drop. The undetectable LOS pressure occurred through two main mechanisms. In $82 \%$ of episodes the LOS underwent complete relaxation against a background of easily recordable basal LOS pressure (type 1) (Fig. 1). In $13 \%$ of episodes, undetectable basal LOS pressure existed for at least 30 seconds before the reflux event (type 2). Mean resting LOS pressure before type 1 reflux episodes was $10 \cdot 1(1 \cdot 0) \mathrm{mmHg}$, whereas that before type 2 reflux episodes was $<2 \mathrm{mmHg}$.

In the $5 \%$ of instances when reflux occurred in the presence of detectable LOS pressure (type 3) the reflux occurred simultaneous with pressure transients generally caused by deep inspiration but occasionally by coughing or straining (Fig. 2). Resting LOS pressure at the time of these pressure transients was almost invariably low $(<5 \mathrm{mmHg})$, and there was usually manometric evidence of an hiatal hernia. Reflux was not observed when strains occurred while LOS pressure was $>10 \mathrm{mmHg}$.

The proportion of reflux episodes associated with the three types of reflux mechanism differed significantly among the study groups $\left(\chi^{2}=55.21, p<0.01\right)$ (Fig. 3). The Group A patients refluxed exclusively via the type 1 mechanism. This mechanism was also the most common pattern associated with reflux episodes occurring in patients with reflux disease. With increasing severity of reflux disease, however, absent basal LOS pressure (type 2) became increasingly more important and accounted for $23 \%$ of reflux episodes in group D. The three patterns were not mutually exclusive in any given patient. Even though many patients exhibited periods of absent 


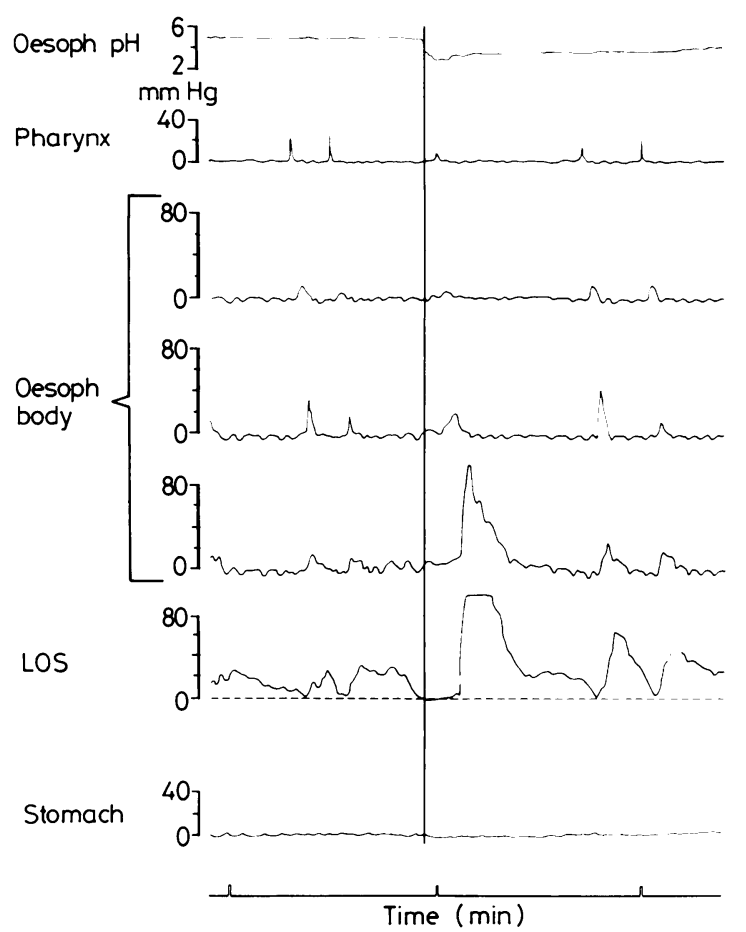

Fig. 1 Gastro-oesophageal reflux occurring during a spontaneous transient lower oesophageal sphincter (LOS) relaxation. Abrupt relaxation of the LOS occurred without any apparent antecedent motor event in the pharynx, oseophageal body or stomach. Shortly after LOS relaxation was complete, the pHelectrode indicated the occurrence of acid reflux.

LOS pressure, particularly in the first post prandial hour, these patients also had periods of moderate LOS pressure, often in excess of 10 to $15 \mathrm{mmHg}$, most commonly during the third and fourth postprandial hours. In the presence of measurable LOS pressure, however, reflux continued to occur because of LOSRs. Only one patient refluxed exclusively because of undetectable LOS pressure.

\section{PATTERNS OF LOS RELAXATION ASSOCIATED WITH REFLUX}

Detailed analysis of the timing of motor events in the pharynx, oesophageal body and LOS, in relation to the onset of type 1 reflux episodes, revealed 6 distinct patterns of LOSR. The most common pattern was an abrupt LOSR that occurred without swallowing or any detectable motor activity in the oesophageal body (spontaneous, transient LOSR) (Fig. 1), and accounted for $31 \%$ of type 1 episodes. These LOSRs had a mean duration of $14.9(0.65) \mathrm{s}$. Almost as common $(22 \%)$ was a LOSR after a normal peri-

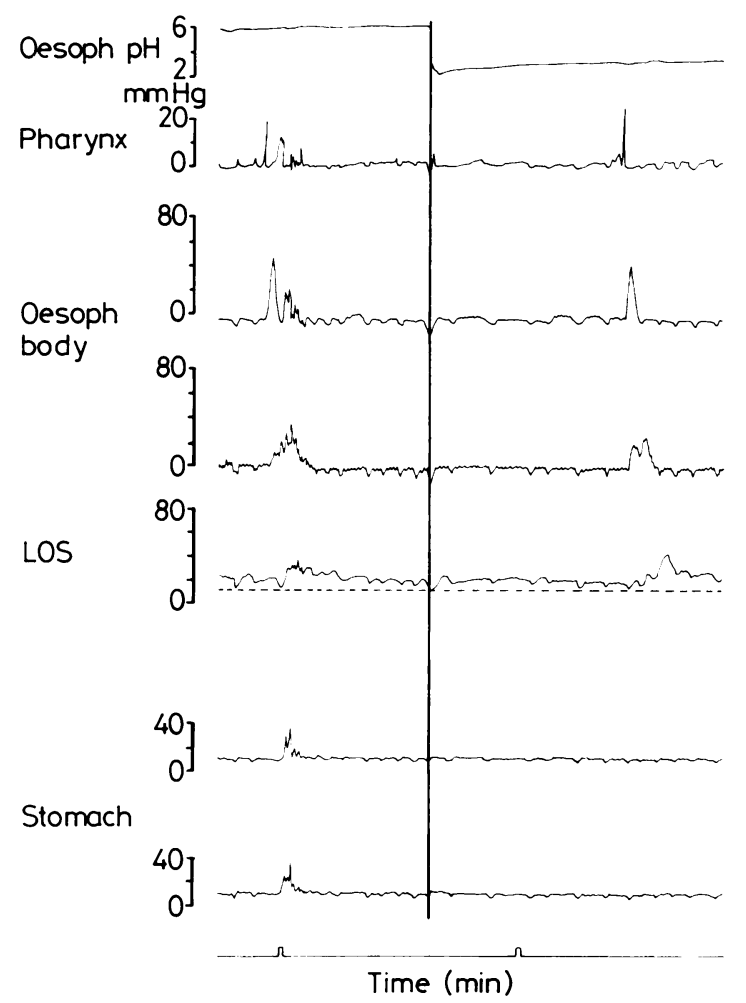

Fig. 2 Gastro-oesophageal reflux occurring in the presence of detectable basal lower oesophageal sphincter (LOS) pressure and a hiatal hernia. In this example, the oesophagus is short and the proximal side hole that is normally in the proximal oesophageal body is in the pharynx. Both gastric pressure tracings show an intrathoracic pattern of respiratory oscillation indicating the presence of an hiatal hernia. Reflux occurs during a large drop in intrathoracic pressure caused by deep inspiration. This drop appears to be transmitted to the LOS and to momentarily negate the pressure barrier created by LCS pressure.

staltic sequence (postswallow transient LOSR), in which the LOS showed a normal contraction after swallow induced relaxation, but then exhibited immediate complete relaxation (Fig. 4). Occasionally $(5 \%)$ similar transient LOSRs were observed after secondary peristalsis or spontaneous synchronous contractions in the distal oesophageal body.

A minority $(28 \%)$ of LOSRs were preceded by a pharyngeal swallow signal. Reflux episodes rarely occurred during LOSRs associated with a normal complete peristaltic sequence (swallow induced LOSR). Although swallow induced LOSRs accounted for $13 \%$ of type 1 reflux episodes overall, 31 of the 65 episodes occurred in one patient. A proportion $(15 \%)$ of reflux episodes, however, did 


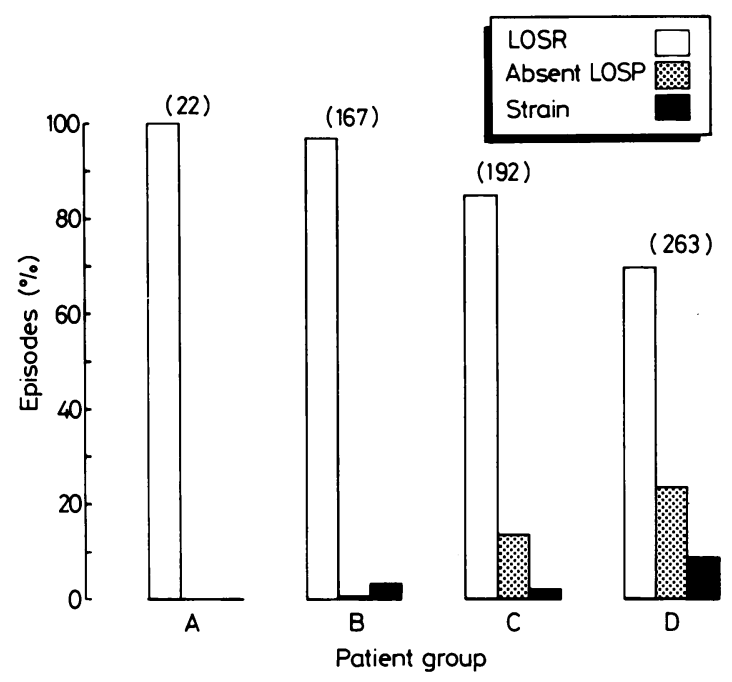

Fig. 3 Mechanisms of reflux among the four patient groups. Each bar represents the percentage of total reflux episodes. The numbers in parentheses indicate the total number of reflux episodes for each group.

occur during LOSRs associated with defective oesophageal peristalsis (failed primary peristalsis), in which swallowing appeared to induce LOS relaxation but either failed to elicit any detectable peristalsis, or the peristaltic wave failed to traverse the entire oesophageal body. These LOSRs were of longer duration than those associated with normal peristalsis. Rarely (3\%), reflux occurred during LOSRs associated with a salvo of swallows in rapid succession (multiple swallows). Lastly, reflux episodes were associated occasionally with a gradual loss of basal LOS pressure during an interval of up to 30 seconds. These episodes, classified as LOS pressure drifts as opposed to LOSRs, accounted for $11 \%$ of type 1 reflux episodes and invariably occurred in a setting of low basal LOS pressure of around $5-10 \mathrm{mmHg}$.

The distribution of mechanisms underlying type 1 reflux episodes among the different patient groups is depicted in Figure 5. Although there were no significant differences amongst the groups, with increasing severity of reflux disease there was a tendency for a greater proportion of reflux episodes to result from slow downward LOS pressure drifts and swallow induced LOSRs.

Reflux episodes that occurred when baseline intraoesophageal $\mathrm{pH}$ was less than 4 were associated with the same patterns of LOS pressure changes as those observed with other reflux episodes. Downward drifts in oesophageal $\mathrm{pH}$, however, occurred without any associated LOS relaxation or straining. They usually occurred in a setting of resting intra-

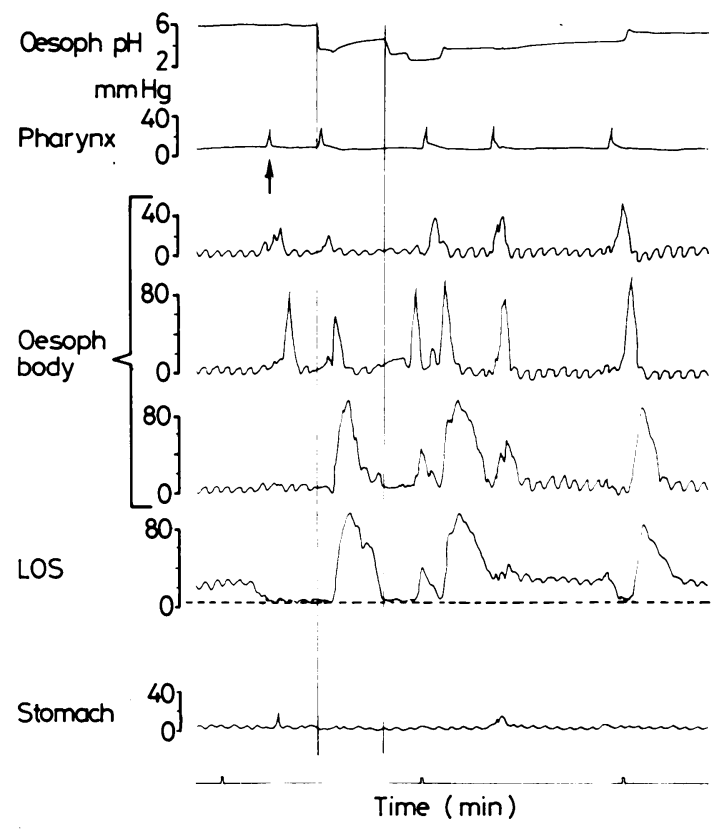

Fig. 4 Two episodes of gastrooesophageal reflux. The first reflux episode occurred during a prolonged spontaneous lower oesophageal sphincter relaxation (LOSR). A swallow (arrow), that occurs after the onset of the LOSR, initiates a peristaltic sequence that fails to propagate along the complete length of the esophagus. The second episode occurred during a transient $L O S$ relaxation ( LOSR) immediately after completion of a normal primary peristaltic sequence (postswallow LOSR).

oesophageal $\mathrm{pH}<5.0$ and often during a prolonged interval without spontaneous swallowing.

OESOPHAGEAL BODY MOTOR FUNCTION DURING TRANSIENT LOSRS

Initial analysis of the mechanisms underlying spontaneous transient LOSRs suggested that during prolonged LOSRs, swallows did not trigger a complete peristaltic sequence. This impression was therefore evaluated systematically. To avoid effects on peristaltic success by surrounding swallows, and to ensure that the LOSR was of sufficient duration to encompass an entire peristaltic sequence, only transient LOSRs with the following features were analysed: (i) duration greater than 15 seconds, (ii) a single swallow occurring after the onset of complete LOS relaxation, and (iii) the swallow being evaluated was separated by at least 15 seconds from adjacent swallows. As a control, the first swallow that occurred more than one minute after termination of the LOSR, and that was separated by at least 15 seconds from adjacent swallows, was analysed for complete- 

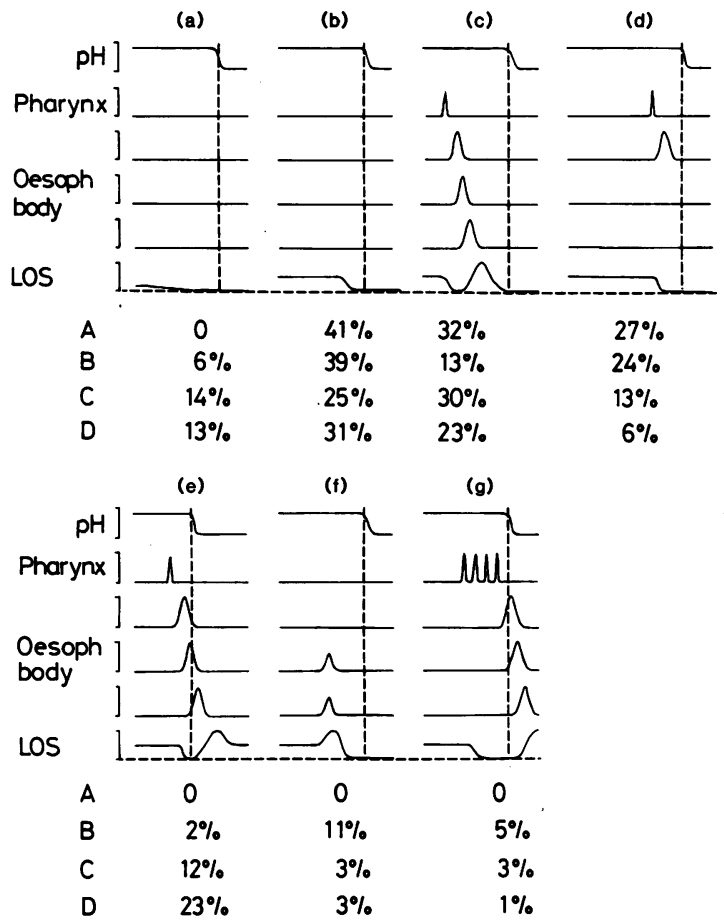

Fig. 5 Schema showing the different patterns of oesophageal and lower oesophageal sphincter (LOS) motor function associated with type 1 reflux events. The numbers below each pattern indicate the percentage of total type 1 episodes for each pattern for each group. The broken horizontal line indicates intragastric pressure. The vertical broken line indicates the onset of the reflux event. (a) LOS pressure drift, (b) spontaneous transient LOS relaxation (LOSR), (c) LOSR occurring immediately after a normal peristaltic sequence (postswallow transient LOSR), (d) LOSR associated with a failed primary peristaltic sequence, (e) reflux during a normal peristaltic sequence, $(f) L O S R$ after spontaneous synchronous contractions in the distal oesophagus, (g) LOSR induced by multiple swallows.

ness of the peristaltic sequence. Twenty three LOSRs in 15 patients fitted the above criteria. Mean duration of these LOSRs was 23 (1) second, and 20 of the 23 LOSRs were associated with a reflux episode. Swallows occurring during these LOSRs triggered complete peristaltic sequences in only two instances (9\%) compared with $100 \%$ of instances with control swallows $(p<0.01)$ (Fig. 6). In the other $91 \%$ of swallows during these prolonged LOSRs, the peristaltic wave was usually observed at only the most proximal oesophageal lead.

BASAL LOS PRESSURE

An inverse relationship existed between basal LOS pressure and the severity of reflux disease. However,

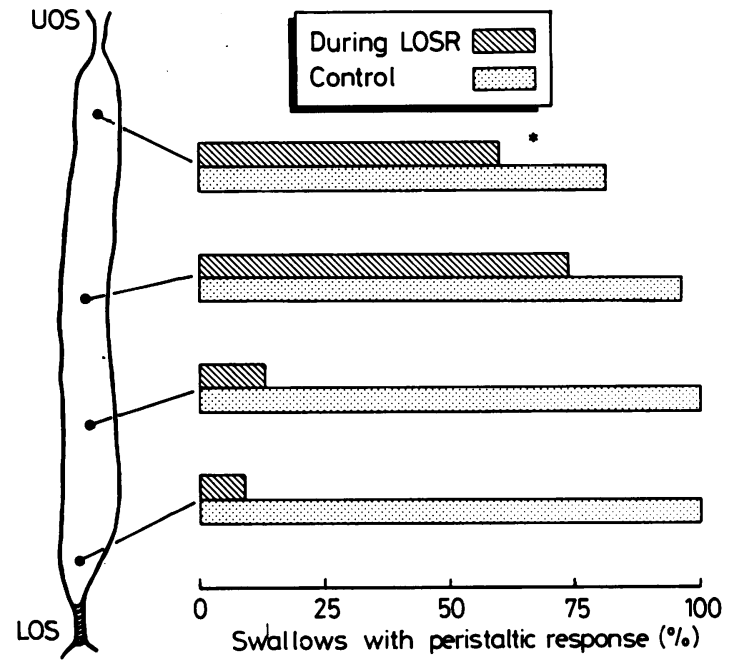

Fig. 6 Analysis of 23 primary peristaltic sequences during transient lower oesophageal sphincter relaxation (LOSR). The horizontal bars indicate the percentage of peristaltic sequences in which a contraction was recorded at that recording site. The asterisk indicates that the most proximal recording site was located in the proximal oesophagus in only five instances. In the rest, the oesophageal body was too short to permit all four recording sites to be in the oesophageal body.

only mean basal LOS pressure in Group D patients $(9 \cdot 7(2 \cdot 1) \mathrm{mmHg})$ differed significantly from that in group A patients $(16.0(2.5) \mathrm{mmHg}, \mathrm{p}<0.01)$. Basal LOS pressure decreased immediately after the meal in all groups, however, a tendency existed for LOS pressure to return to and exceed fasting values after the second postprandial hour.

\section{Discussion}

In this study of a large heterogeneous group of patients with symptomatic GOR we have examined in detail the oesophageal motor events surrounding episodes of acid reflux. Our findings indicate that transient LOSRs are the major mechanism of reflux in patients with severe ulcerative peptic oesophagitis as well as symptomatic GOR disease. The proportion of reflux episodes occurring via this mechanism in patients with erosive of ulcerative eosophagitis is similar to the $55 \%$ we observed in our previous study of 10 patients with oesophagitis of comparable severity. ${ }^{9}$

The finding that patients judged not to have symptomatic GOR refluxed exclusively during transient LOSRs is in keeping with the findings of our previous study in normal subjects. ${ }^{8}$ Furthermore, the mix of patterns of transient LOSR, the rate of reflux 
episodes and the duration of acid exposure were comparable with those in the normal subjects. Thus whilst the patients in Group A are not strictly control subjects, they are nevertheless a useful control group with which to compare to other patients with reflux disease.

As noted by others, ${ }^{5}$ basal LOS pressure was lower in patients with severe degrees of oesophagitis. Additionally, absent basal LOS pressure became a progressively more important mechanism of reflux the more severe the oesophagitis. The actual proportion of reflux episodes that occurred by this mechanism was small, however, even in patients with severe oesophagitis, and only one patient refluxed exclusively by this means. In all patients who had absence of basal pressure, this was an intermittent phenomenon, but they continued to reflux during periods of detectable LOS pressure because of LOSRs. This finding provides a possible explanation for the failure of drugs that raise basal LOS pressure to control reflux ${ }^{13}$ and suggests that the pharmacotherapy of disordered motor function in reflux disease would be better directed at control of transient LOSRs than towards augmentation of basal LOS pressure.

Detailed analysis of oseophageal motility surrounding the reflux events, revealed six principle patterns of LOS relaxation. Consistent with our previous findings ${ }^{89}$ and those of others ${ }^{14}$ in normal subjects, the majority of LOSRs were not directly preceded by a pharyngeal swallow signal. This finding, however, is at variance with two recent studies which have suggested that the majority of reflux episodes are directly related to swallowing. ${ }^{1516}$ The reason for this disparity is not readily apparent, but may result in part from suboptimal methodology and data analysis in the previous studies. One of these studies was severely limited by recording methods because the single side hole sensor used to record LOS pressure was considered to have monitored LOS pressure adequately during only $18 \%$ of the reflux episodes. ${ }^{15}$ In the other study, ${ }^{16}$ details of the analysis of the timing of swallowing relative to the onset of the reflux episode were not specified. The timing of the pharyngeal swallow signal relative to the onset of the LOSR, however, is crucial. Our analysis reveals that most of the swallows that preceded reflux episodes actually occurred after the onset of the transient LOSR and may have been the consequence of reflux. Such swallows could not have been the trigger of transient LOSRs since the LOSRs associated with normal primary peristalsis had their onset after pharyngeal contraction was recorded.

Reflux episodes were recorded only rarely during swallow induced LOS relaxation associated with a normal peristaltic sequence, either because reflux did not occur or because the oncoming wave of contrac- tion limited any refluxate to the distal oesophagus beyond the $\mathrm{pH}$ electrode. Although a small proportion of LOSRs appear to be directly swallow related, most of these are associated with failed peristaltic sequences. The inhibition of oesophageal motor body activity that we have shown to accompany prolonged transient LOSRs raises the possibility that some of these apparently failed peristaltic sequences may have resulted from the chance association of a spontaneous transient LOSR and a swallow.

On occasions, swallows occurred after the occurrence of transient LOSRs but just before the onset of oesophageal acidification. The role of such swallows in the triggering of reflux is not clear. The factors that maintain gastrooesophageal competence during apparent complete LOS relaxation are not adequately understood. Possibly, shortening of the oesophagus induced by swallowing ${ }^{17}$ may exert traction on the LOS and help overcome any residual forces which maintain sphincter competence during LOS relaxation.

The abruptness of transient LOSRs suggests that they are mediated by a neural mechanism. This notion is supported by our recent demonstration in the dog that blockade of both cervical vagosympathetic bundles ${ }^{18}$ and light general anaesthesia ${ }^{19}$ abolishes transient LOSRs associated with belching, and that gaseous gastric distension does not provoke these events in patients with achalasia. ${ }^{20}$ This view is further supported by our analysis of oesophageal body motor function during prolonged transient LOSRs. The demonstration of refractoriness of the smooth muscle oesophagus is only readily explainable by neural inhibition. The duration of transient LOSRs suggests that this inhibition may be stronger and of longer duration than that which occurs during normal swallow induced LOS relaxation. Relatively long lasting LOS and oesophageal body inhibition would be expected to facilitate reverse transit in the oesophagus, consistent with the proposed normal role of transient LOSRs, that of controlled orad venting of gastric contents. ${ }^{21}$

Little is known about triggers for transient LOSRs. Gastric distension is the most potent stimulus yet identified. ${ }^{21}{ }^{22}$ Our data indicate that most transient LOSRs are not triggered by swallowing as they are not associated with a manometrically recordable pharyngeal signal. It has been suggested recently, that transient LOSRs may result from partial activation of the excitatory component of primary peristalsis with more complete stimulation of LOS inhibitory mechanisms mediated by a long train vagal stimulus. ${ }^{1423}$ The inhibition of oesophageal peristalsis that we observed during prolonged LOSRs could be explained by a long train vagal discharge but in the opossum, transient LOSRs associated with partial 
activation of the swallow reflex were largely incomplete and of shorter duration than those associated with complete swallows. ${ }^{23}$ This finding is in marked contrast to spontaneous LOSRs in the present study which were complete and of longer duration than swallow induced LOSRs, and argues against the hypothesis that all LOSRs result from partial or complete expression of the swallow reflex.

The basal LOS hypotonia present in some patients with peptic oesophagitis, has been ascribed to either dysfunction of the circular smooth muscle ${ }^{24}$ or defective tonic neural control. ${ }^{25}$ Absent basal LOS pressure was never present consistently throughout the study period in any of our patients, all of whom manifested at some time detectable LOS pressure sufficient to prevent reflux. Indeed many patients with undetectable fasting or immediately postprandial basal LOS pressures subsequently developed considerable LOS pressure. This pressure was often in the region of 15 to $20 \mathrm{mmHg}$ in the second or third postprandial hour and was maintained until the end of the study. Thus, the sphincter muscle in these patients was capable of normal contraction for sustained periods of time, indicating adequate contractility of the LOS smooth muscle, thereby implying a defect in neural control. Defective neural control of basal LOS pressure also provides a plausible explanation for the increased prevalence of LOS pressure drifts that we observed in patients with low basal LOS pressure.

Based on the findings of this study, we propose that excessive reflux in gastrooesophageal reflux disease may be caused, at least in part, by a spectrum of deranged neural control of LOS pressure. At one end of the spectrum, basal LOS pressure is normal but an abnormally high reflux rate occurs because of an increased sensitivity of the neural control mechanisms that trigger transient LOSRs. At the other end of the spectrum, gross LOS hypotonia reflects, at least in part, a persistent defect in the neural mechanisms which maintain basal LOS pressure. Between these poles of the spectrum, are patients who have a partial defect in the neural mechanisms that normally maintain basal LOS pressure resulting in intermittent episodes of absent basal LOS pressure and an increased tendency for LOS pressure to drift transiently to excessively low values.

This work was presented in part at the Annual Meeting of the American Gastroenterological Association, Washington, DC, 1983 and published in abstract form in Gastroenterology 1983; 84: 1135. This work was supported by a project research grant from the Australian National Health and Medical Research Council. We gratefully acknowledge the technical assistance of Ian Lewis and the late Beverley Barnes.

\section{References}

1 Wankling WJ, Warrian WG, Lind JF. The gastroesophageal sphincter in hiatus hernia. Can J Surg 1965; 8: 61-7.

2 Pope CE II. A dynamic test of sphincter strength: its application to the lower esophageal sphincter. Gastroenterology 1967; 52: 779-86.

3 Cohen S, Harris LD. Does hiatus hernia affect competence of the gastroesophageal sphincter? $N$ Engl J Med 1971; 284: 1053-6.

4 Fisher RS, Malmud LS, Roberts GS, Lobis IF. The lower esophageal sphincter as a barrier to gastroesophageal reflux. Gastroenterology 1977; 72: 19-22.

5 Behar J, Biancani P, Sheahan DG. Evaluation of esophageal tests in the diagnosis of reflux esophagitis. Gastroenterology 1976; 71: 9-15.

6 Krejs GJ, Seefeld V, Brandlii $\mathrm{HH}$, et al. Gastrooesophageal reflux disease: correlation of subjective symptoms with 7 objective oesophageal function tests. Acta Hepato-Gastroenterol 1976; 23: 130-40.

7 Stanciu C, Hoare RC, Bennett JR. Correlation between manometric and $\mathrm{pH}$ tests for gastro-oesophageal reflux. Gut 1977; 18: 536-40.

8 Dent J, Dodds WJ, Friedman RH, et al. Mechanism of gastroesophageal reflux in recumbent asymptomatic human subjects. J Clin Invest 1980; 65: 256-67.

9 Dodds WJ, Dent J. Hogan WJ, et al. Mechanisms of gastroesophageal reflux in patients with reflux esophagitis. N Engl J Med 1982; 307: 1547-52.

10 Dent J. A new technique for continuous sphincter pressure measurement. Gastroenterology 1976; 71: 263-7.

11 Dent J, Dodds WJ, Sekiguchi T, Hogan WJ, Arndorfer RC. Interdigestive phasic contractions of the human lower esophageal sphincter. Gastroenterology 1983; 84: 453-60.

12 Orr WC, Robinson MG, Johnson LF. Acid clearance during sleep in the pathogenesis of reflux esophagitis. Dig Dis Sci 1981; 26: 423-7.

13 Hyams JS, Leichtner AM, Zamett LO, Walters JK. Effect of metoclopramide on prolonged intraesophageal $\mathrm{pH}$ testing in infants with gastroesophageal reflux. J Pediatr Gastroenterol Nutr 1986; 5: 716-20.

14 Mittal RK, McCallum RW. Characteristics of transient lower esophageal sphincter relaxation in humans. $\mathrm{Am} \mathrm{J}$ Physiol 1987; 252: G636-41.

15 Corazziari E. Bontempo I, Anzini F, Torsoli A. Motor activity of the distal oesophagus and gastro-oesophageal reflux. Gut 1984; 25: 7-13.

16 Baldi F, Ferrarini F, Balestra R, et al. Oesophageal motor events at the occurrence of acid reflux during endogenous acid exposure in healthy subjects and in patients with oesophagitis. Gut 1985; 26: 336-41.

17 Dodds WJ, Stewart ET, Hodges D, Zboralske FF. Movement of the feline esophagus associated with respiration and peristalsis. $J$ Clin Invest 1973 ; 52: 1-13.

18 Martin CJ, Patrikios J, Dent J. Abolition of gas reflux 
and transient lower esophageal sphincter relaxation by vagal blockade. Gastroenterology 1986; 91: 890-6.

19 Cox MR, Martin CJ, Westmore M, Dent J. Effect of general anaesthesia on transient lower esophageal sphincter relaxation in the dog [Abstract]. Gastroenterology 1987; 92: 1357.

20 Holloway RH, Dent J, Wyman JB. Impairment of belching in achalasia: evidence for neural mediation of transient lower esophageal sphincter (LES) relaxations [Abstract]. Gastroenterology 1986; 91: 1055.

21 Wyman JB, Dent J, Heddle R, Dodds WJ, Toouli J, Lewis I. Belching: a clue to understanding of pathological gastroesophageal reflux [Abstract]. Gastroenterology 1984; 86: 1303.
22 Holloway RH, Hongo M, Berger K, McCallum RW. Gastric distension: a mechanism for post-prandial gastroesophageal reflux. Gastroenterology 1985; 89: 779-84.

23 Paterson WG, Rattan S, Goyal RK. Experimental induction of isolated esophageal sphincter relaxation in anaesthetised opossums. J Clin Invest 1986; 77: 1187-93.

24 Grossman MI. Do refluxers have sick sphincters? N Engl J Med 1974; 290: 167.

25 Higgs RH, Castell DO, Eastwood GL. Studies on the mechanism of esophagitis induced lower esophageal sphincter hypotension in cats. Gastroenterology 1976; 71: 51-7. 